\title{
Molecular mechanism of lipid-induced cardiac insulin resistance and contractile dysfunction
}

Citation for published version (APA):

Liu, Y., Neumann, D., Glatz, J. F. C., \& Luiken, J. J. F. P. (2018). Molecular mechanism of lipid-induced cardiac insulin resistance and contractile dysfunction. Prostaglandins Leukotrienes and Essential Fatty Acids, 136, 131-141. https://doi.org/10.1016/j.plefa.2016.06.002

Document status and date:

Published: 01/09/2018

DOI:

10.1016/j.plefa.2016.06.002

Document Version:

Publisher's PDF, also known as Version of record

Document license:

Taverne

Please check the document version of this publication:

- A submitted manuscript is the version of the article upon submission and before peer-review. There can be important differences between the submitted version and the official published version of record.

People interested in the research are advised to contact the author for the final version of the publication, or visit the DOI to the publisher's website.

- The final author version and the galley proof are versions of the publication after peer review.

- The final published version features the final layout of the paper including the volume, issue and page numbers.

Link to publication

\footnotetext{
General rights rights.

- You may freely distribute the URL identifying the publication in the public portal. please follow below link for the End User Agreement:

www.umlib.nl/taverne-license

Take down policy

If you believe that this document breaches copyright please contact us at:

repository@maastrichtuniversity.nl

providing details and we will investigate your claim.
}

Copyright and moral rights for the publications made accessible in the public portal are retained by the authors and/or other copyright owners and it is a condition of accessing publications that users recognise and abide by the legal requirements associated with these

- Users may download and print one copy of any publication from the public portal for the purpose of private study or research.

- You may not further distribute the material or use it for any profit-making activity or commercial gain

If the publication is distributed under the terms of Article $25 \mathrm{fa}$ of the Dutch Copyright Act, indicated by the "Taverne" license above, 


\title{
Molecular mechanism of lipid-induced cardiac insulin resistance and contractile dysfunction
}

\author{
Yilin Liu, Dietbert Neumann, Jan F.C. Glatz *, Joost J.F.P. Luiken \\ Department of Molecular Genetics, Cardiovascular Research Institute Maastricht (CARIM), Maastricht University, P.O. Box 616, 6200 MD Maastricht, The \\ Netherlands
}

\section{A R T I C L E I N F O}

\section{Article history:}

Received 24 May 2016

Accepted 10 June 2016

\section{Keywords:}

Cardiac fatty acid uptake

Lipid-induced insulin resistance

CD36

Diabetic cardiomyopathy

\begin{abstract}
A B S T R A C T
Long-chain fatty acids are the main cardiac substrates from which ATP is generated continually to serve the high energy demand and sustain the normal function of the heart. Under healthy conditions, fatty acid $\beta$-oxidation produces $50-70 \%$ of the energy demands with the remainder largely accounted for by glucose. Chronically increased dietary lipid supply often leads to excess lipid accumulation in the heart, which is linked to a variety of maladaptive phenomena, such as insulin resistance, cardiac hypertrophy and contractile dysfunction. CD36, the predominant cardiac fatty acid transporter, has a key role in setting the heart on a road to contractile dysfunction upon the onset of chronic lipid oversupply by translocating to the cell surface and opening the cellular 'doors' for fatty acids. The sequence of events after the CD36-mediated myocellular lipid accumulation is less understood, but in general it has been accepted that the excessively imported lipids cause insulin resistance, which in turn leads to contractile dysfunction. There are several gaps of knowledge in this proposed order of events which this review aims to discuss. First, the molecular mechanisms underlying lipid-induced insulin resistance are not yet completely disclosed. Specifically, several mediators have been proposed, such as diacylglycerols, ceramides, peroxisome proliferator-activated receptors (PPAR), inflammatory kinases and reactive oxygen species (ROS), but their relative contributions to the onset of insulin resistance and their putatively synergistic actions are topics of controversy. Second, there are also pieces of evidence that lipids can induce contractile dysfunction independently of insulin resistance. Perhaps, a more integrative view is needed, in which several lipid-induced pathways operate synergistically or in parallel to induce contractile dysfunction. Unraveling of these processes is expected to be important in designing effective therapeutic strategies to protect the lipid-overloaded heart.
\end{abstract}

(c) 2016 Elsevier Ltd. All rights reserved.

\section{Introduction}

ATP is required as a primary energy source to maintain the contractile function of the healthy heart. Long-chain fatty acids, together with glucose, present the major substrates for cardiac ATP production. For this, the fatty acids undergo $\beta$-oxidation in the mitochondria of the cardiomyocytes, yielding acetyl-CoA that enters the Krebs cycle to result in NADH and $\mathrm{FADH}_{2}$. These latter reduced coenzymes deliver their high-energy electrons to the electron transfer chain for the establishment of a mitochondrial proton gradient and the associated production of ATP [1,2]. Fatty acids have the advantage over the second important energy substrate glucose in that, when oxygen delivery is not limited, they provide more ATP per molecule and that they can be more optimally stored, namely as triacylglycerols. Yet, despite their crucial

\footnotetext{
* Corresponding author.

E-mail address: glatz@maastrichtuniversity.nl (J.F.C. Glatz).
}

role in cardiac energy provision, fatty acids can initiate a chain of harmful events, especially when their supply continuously exceeds the metabolic demands of the heart. Such situation frequently arises upon sustained dietary lipid overconsumption as part of the Western lifestyle. Specifically, fatty acid oversupply gives rise to an imbalance between fatty acid uptake and oxidation, resulting in lipid accumulation in the cardiomyocytes [3]. Over time, lipid accumulation develops into a maladaptive state described as lipotoxicity', which refers to a condition in which lipids have accumulated to such levels that they become toxic to the cells. The latter implies a loss of contractile activity which is the main function of cardiomyocytes. At the level of the heart, there is decreased pump function, a state referred to as lipid-induced cardiomyopathy, which has been recognized as a major cause of death in type-2 diabetic patients.

The mechanisms by which lipids induce cardiac contractile dysfunction have been subject to intensive research, but until now remain only partly understood. However, it has become clear that myocellular lipid accumulation leads to the development of insulin 
resistance, which is defined as a metabolic state in which the cells are unable to respond properly to insulin (i.e., by increasing glucose uptake and accumulate glycogen). Subsequently, insulin resistance may lead to contractile dysfunction. There has been a debate on the possible molecular mechanisms by which lipids induce insulin resistance. Several possibilities have been described, including formation of 'toxic' lipid intermediates (diacylglycerols, ceramides), activation of peroxisome proliferator-activated receptors (PPARs), ROS production and the onset of inflammation. Surprisingly, little is known about the molecular mechanisms triggered by the insulin resistant state that result in an impairment of cardiac contractile function. On the other hand, lipids may cause contractile dysfunction independently of insulin resistance. Possible mechanisms for such lipid action may include effects on caveolins and/or direct sterical hindrance of the contractile apparatus. Most likely, in the heart (excess) lipids set in motion a pleiotropy of maladaptive actions some of which act through insulin resistance and some of which act in a different manner.

This review aims to provide an overview of possible mechanisms of lipid-induced insulin resistance and contractile dysfunction with an attempt to integrate insulin-resistance-dependent and independent pathways within a scheme of lipid-induced contractile dysfunction. First, we will introduce the lipid metabolic pathways and insulin signaling kinases that are operative in the heart and subject to changes during lipid overload (Sections 2 and 3). Then, in Section 3, lipid-induced translocation of the fatty acid transporter CD36 is presented as the key early event in cardiac lipid oversupply and as causal factor in myocardial lipid accumulation. Finally, we will discuss in detail the suggested various mechanisms underlying lipid-induced contractile dysfunction (Sections 4-6).

\section{Cardiac fatty acid metabolism}

Fatty acids provide $50-70 \%$ of the energy for cardiac contractile activity. The majority of fatty acids enter the cardiomyocytes via protein-mediated transport, whereas passive diffusion to a lesser extent contributes to bulk uptake of fatty acids [4]. The heart expresses various membrane-associated proteins facilitating fatty acid uptake and which, for convenience, often are designated as fatty acid transporters, including plasma membrane fatty acidbinding protein (FABPpm), CD36, fatty acid-transport protein-1 (FATP1), and FATP6. CD36 was observed to be responsible for the bulk uptake ( $>70 \%$ ) of fatty acids, which finding was based on studies of substrate uptake kinetics in cardiomyocytres from CD36 knockout versus wild-type mice [5].

CD36 is an integral membrane protein with two membranespanning regions enclosing a large extracellular loop which contains the fatty acid-binding pocket [6]. CD36 not only is present at the sarcolemma, but also is stored intracellularly, i.e., within endosomal membranes. This endosomal storage is most prominent under conditions of a low demand for energy, whereby $\sim 50 \%$ of the CD36 population is present within endosomes [7]. Two major physiological stimuli, i.e., (i) increased metabolic demands (resulting from increased workload) and (ii) increased circulating insulin levels, induce the translocation of endosomal CD36 to the cell surface, leading to increased fatty acid uptake. Stimulation of CD36 translocation by increased metabolic demands requires activation of the cell's major energy sensor AMP-activated kinase (AMPK), while insulin-stimulated CD36 translocation requires activation of Akt2 (see Section 3) [8]. CD36 translocation is a vesiclemediated process, involving coat proteins for vesicle budding, Rab proteins for providing the unidirectionality in vesicle transport, and SNARE proteins for the specificity of trafficking [7]. Under non-stimulated (resting) conditions, Rab proteins are kept in an inactive state by the Rab-GTPase action of Akt substrate of $160 \mathrm{kDa}$ (AS160). Both Akt and AMPK inhibit AS160 via phosphorylation, leading to de-inhibition of the Rabs, and subsequent stimulation of CD36 translocation. In all these aspects, CD36 translocation closely resembles the well-characterized process of GLUT4 translocation, which is also stimulated by increased metabolic demands and insulin via activation of AMPK and Akt2, respectively, leading to AS160 phosphorylation and stimulation of glucose uptake [7].

Following their uptake into cardiomyocytes and subsequent transport through the cytoplasm by the small $(15 \mathrm{kDa})$ cytoplasmic heart-type fatty acid-binding protein (FABPc), fatty acids are rapidly converted into acyl-CoA esters by fatty acyl-CoA synthase (FACS) located at the outer mitochondrial membrane. In the heart, acyl-CoA esters have two major metabolic fates: mitochondrial $\beta$-oxidation and storage as triacylglycerol in lipid droplets.

In the healthy heart, fatty acids are primarily destined for mitochondrial $\beta$-oxidation, of which carnitine palmitoyl transferase 1 (CPT1) is the major gatekeeper. Under low energy demands CPT1 is kept in a relatively inactive state via its negative regulator malonyl-CoA. Increased metabolic demands activate CPT1 by inhibiting malonyl-CoA production via acetyl-CoA carboxylase (ACC). The underlying mechanism includes activation of AMPK, which phosphorylates and thereby inhibits ACC. CPT1 then converts acylCoA into acyl-L-carnitine. Given that AMPK also phosphorylates AS160 for stimulation of CD36 translocation, the coordinated phosphorylation of both AS160 and CPT1 ensures that under high energy demands increased fatty acid uptake is tightly linked to subsequent mitochondrial $\beta$-oxidation. Once inside the mitochondria, acyl-L-carnitine is converted back to fatty acyl-CoA by carnitine palmitoyl transferase 2 (CPT-2). Fatty acyl CoA then enters the $\beta$-oxidation pathway to produce acetyl CoA, NADH, and $\mathrm{FADH}_{2}[9,10]$. A schematic overview of fatty acid metabolism in cardiomyocytes is provided in Fig. 1.

Excess fatty acyl-CoA, i.e., not passing CPT1 for mitochondrial $\beta$-oxidation, is converted into triacylglycerol in a stepwise fashion by consecutive actions of glycerol-3-phosphate acyltransferase (GPAT), lipin, and diacylglycerol-acyltransferase (DGAT), rendering the process of triacylglycerol synthesis to serve as an overflow pathway for mitochondrial $\beta$-oxidation. Triacylglycerol is stored within a hydrophobic core of neutral lipid surrounded by a phospholipid monolayer and associated proteins, and the whole structure is referred to as lipid droplet. Among the lipid dropletassociated proteins are adipose triacylglycerol lipase (ATGL) and hormone-sensitive lipase (HSL) which each will mediate the liberation of fatty acid moieties from these droplets for mitochondrial $\beta$-oxidation when the energy requirements exceed the fatty acid supply [11].

\section{Insulin signaling in the heart and insulin resistance}

Insulin plays a key role in the regulation of substrate transport and utilization in the heart, by stimulating both cardiac glucose and fatty acid uptake via GLUT4 and CD36 translocation, respectively [7]. Insulin signal transduction in cardiomyocytes comprises a complex series of events initiated by activation of the insulin receptor (IR) tyrosine kinase, which is followed by tyrosine phosphorylation of insulin receptor substrates 1 and -2 (IRS-1/2). IRS phosphorylation activates phosphatidylinositol 3-kinase (PI3K), the main player of the metabolic action of insulin. PI3K then associates with the plasma membrane, where it phosphorylates inositol phospholipids to produce phosphatidylinositol $(3,4$, 5)-trisphosphate ( $\left.\mathrm{PIP}_{3}\right)$. The increase in $\mathrm{PIP}_{3}$ at the plasma membrane induces the recruitment and activation of the 


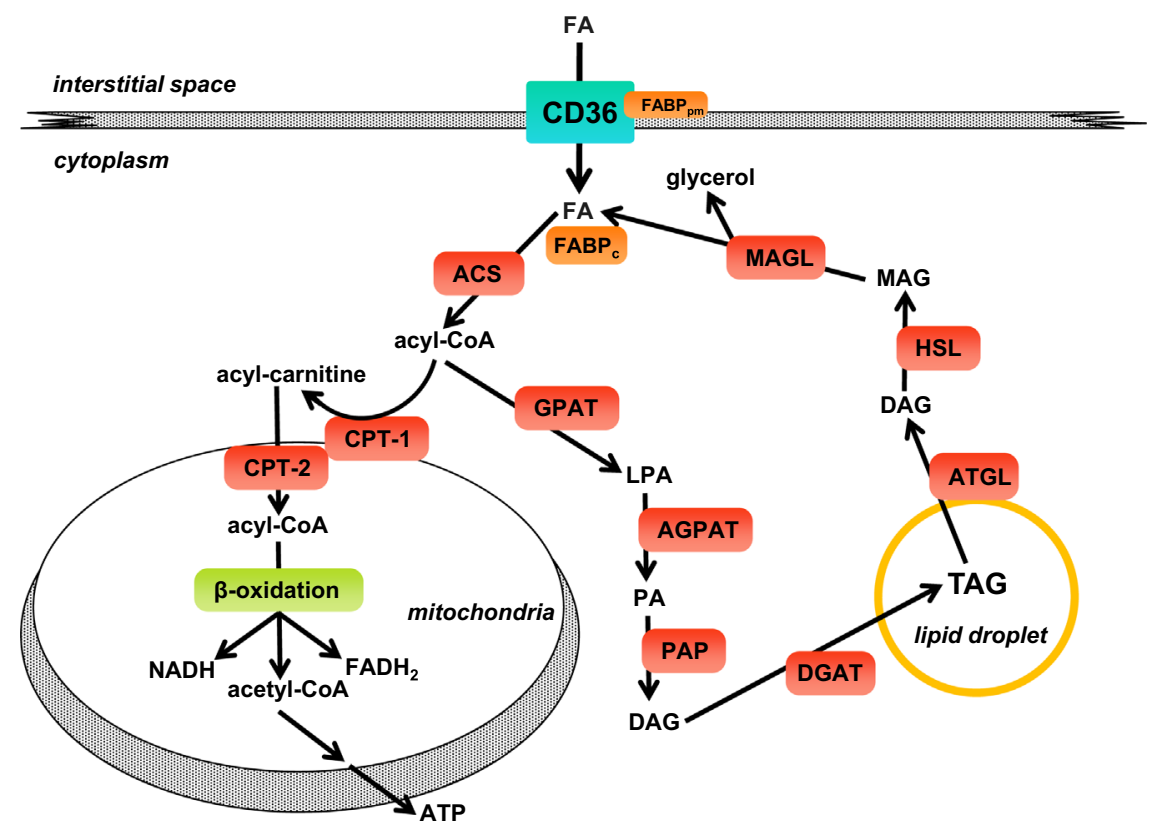

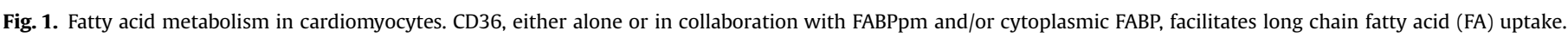

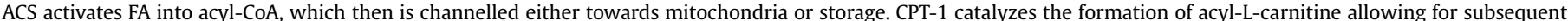

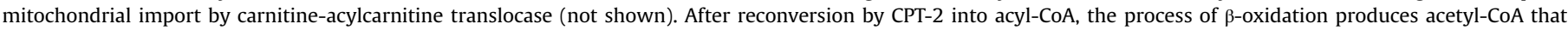

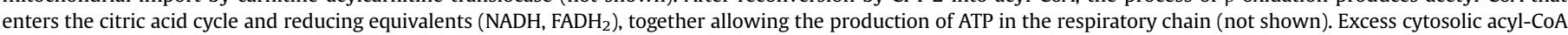

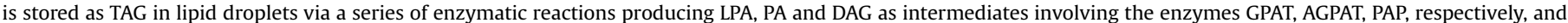

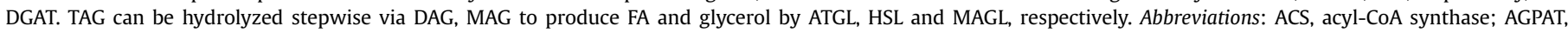

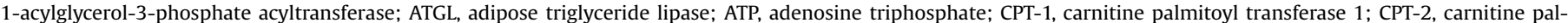

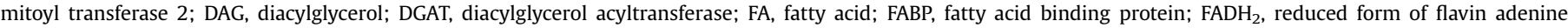

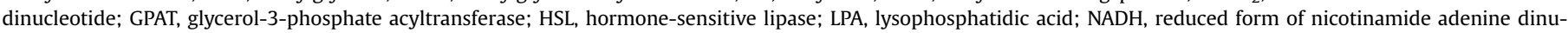
cleotide; PA, phosphatidic acid; PAP, phosphatidate phosphatase-1; MAG, monoacylglycerol; MAGL, monoacylglycerol lipase; TAG, triacylglycerol.

phosphoinositide-dependent kinase 1 (PDK1), which further phosphorylates and activates PKB/Akt [12]. Akt exists in three isoforms of which Akt2 regulates cardiac metabolism [13]. Akt is at the crossroads of many signaling pathways and has quite a number of cellular targets. For insulin-stimulated glucose uptake, Akt2's phosphorylation of AS160 is especially important [8], as mentioned in the previous section. Upon stimulation with insulin, AS160 is found to be phosphorylated on at least five sites, one of which is the 14-3-3 binding phospho-Thr649 in mice, as equivalent to Thr642 in human AS160 [14,15]. Studies indicate that mice in which AS160-Thr649 is replaced by a non-phosphorylatable alanine residue are glucose intolerant, and show decreased insulin sensitivity and altered GLUT4 trafficking [15]. In parallel to PKB/ Akt, PDK1 activates the atypical protein kinase $C$ (PKC) isoforms $\lambda$ and $\zeta$, which contribute to the translocation of GLUT4, and hence stimulate glucose uptake $[16,17]$.

When lipid supply is chronically increased, either in vitro or in vivo, the ability of this canonical insulin signaling pathway to respond to insulin is drastically diminished. First, upon lipid oversupply, the delicate balance between CD36-mediated fatty acid uptake, mitochondrial $\beta$-oxidation, fatty acid storage and triacylglycerol hydrolysis, as present in the healthy heart, becomes challenged. When examining the time course of development of lipid-induced insulin resistance in vivo in rat skeletal muscle, a net translocation of CD36 from endosomes to the sarcolemma was one of the first changes observed (within 3 days after the start of the high fat diet regime) [18]. In heart and muscle, this CD36 translocation then causes a chronical increase in basal fatty acid uptake while at the same time insulin-stimulated fatty acid uptake is lost $[18,19]$ (Fig. 2). This suggests that the CD36 pool that is stored in insulin-responsive endosomal sub-compartments is responsible for the chronic increase in fatty acid uptake. Very rapidly after CD36 translocation and increased fatty acid uptake, i.e., within the same day, accumulation of lipid species (triacylglycerols, diacylglycerols and ceramides) in muscle was observed [18]. In contrast, changes in insulin signaling and insulin-stimulated glucose uptake occurred much later, i.e., after three weeks of high fat diet. Importantly, these latter changes are dependent on increased CD36 translocation, as CD36 ablation protects against high fat dietinduced insulin resistance [18]. Changes in mitochondrial parameters also occurred not until after three weeks [18]. Also in heart, a similar early increase in CD36 translocation was observed together with a loss in contractile function that followed much later (between 4 and 8 weeks) [19]. Hence, this rapid CD36 translocation event is a key determinator of lipid-induced insulin resistance and contractile dysfunction. Moreover, the time lag between CD36 translocation and lipid accumulation on one hand, and insulin resistance and contractile dysfunction on the other, may suggest that the underlying molecular processes are time-consuming and complex (Fig. 2).

In the remainder of this review we will present the various proposed mechanisms that may explain how lipids can give rise to cardiomyopathy and heart failure. As mentioned above, these lipid-triggered adaptations may include the development of insulin resistance, or alternatively may induce cardiomyopathy in a direct manner independent from insulin resistance. In the latter scenario, insulin resistance rather would be an innocent bystander or perhaps even a compensatory process. The mechanisms upstream of lipid-induced CD36 translocation are currently unknown and remain outside the scope of this review. First, we will discuss the possible routes from lipids to cardiomyopathy including insulin resistance. Then, we will discuss the possibility of lipid-induced cardiac dysfunction independent of insulin resistance. Finally we aim to present an integrative view of the various mechanisms involved. 

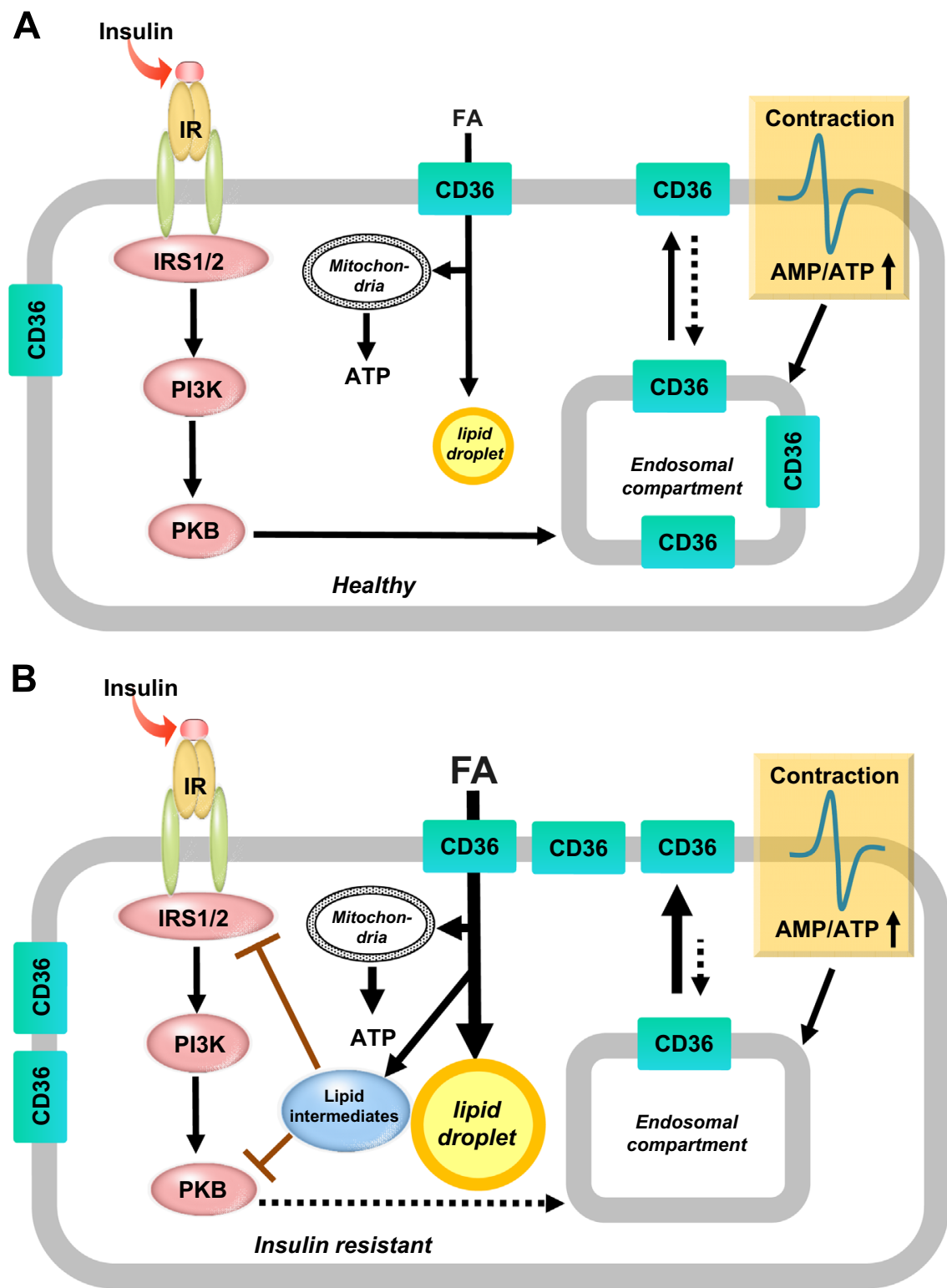

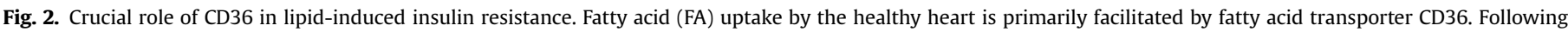

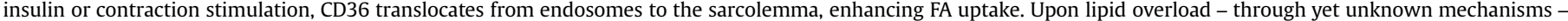

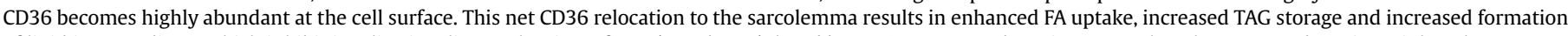

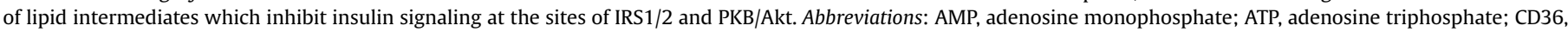
fatty acid translocase FAT/CD36; IR, insulin receptor; IRS1/2, IR substrate 1/2; PI3K, phosphoinositide 3-kinase; PKB, protein kinase B/Akt; TAG, triacylglycerol.

\section{Mediators of lipid-induced insulin resistance}

When any of the kinases involved in the insulin signaling cascade is impaired, symptoms of insulin resistance would develop. Several lipid metabolites, especially diacylglycerols and ceramides, affect insulin signaling [20,21]. During chronic lipid oversupply, all lipid metabolizing pathways become saturated so that the concentration of a great number of lipid metabolites increases. First, the combined actions of CD36 and FACS, i.e., coupling of fatty acid uptake to rapid conversion of fatty acids into acyl-CoA, ensure the maintenance of a steep fatty acid gradient from outside-to-inside the cell, and therefore a chronically increased fatty acid influx, which underlies all subsequent changes in fatty acid metabolism. Diacylglycerol will be generated in the triacylglycerol synthesis pathway by the phosphatidate phosphatase action of lipin, and in the triacylglycerol degradation route by the lipolytic actions of ATGL and HSL. Parts of the fatty acyl-CoA overshoot are covalently coupled to serine by serine-palmitoyltransferase leading to ceramide production. The most prominent hallmarks of lipid accumulation, the triacylglycerols stored in lipid droplets, are considered inert, and would not alter insulin signaling directly. Additionally, other factors, including PPARs, inflammatory molecules, and reactive oxygen species (ROS), have been proposed to mediate lipid-induced insulin resistance. The molecular mechanisms by which these factors may act, is discussed below in a pointwise manner. Yet, this list is not complete as various other possibilities, such as the roles of uncoupling proteins (at the most a minor contribution) and endoplasmic reticulum stress (more important in liver) are not discussed.

\subsection{Diacylglycerol}

Diacylglycerol is known to be a potent activator of both conventional and novel PKC isoforms [22,23] (Bronfman; Nishizuka). The PKC family consists of three subfamilies, based on their second messenger requirement: conventional $(\alpha, \beta$ and $\gamma)$, novel $(\delta, \varepsilon, \eta$, 
and $\theta$ ), and atypical PKC's ( $\zeta$ and $\lambda$ ) [23]. Conventional PKC activation is the result of binding of calcium to the $\mathrm{C} 2$ domain, increasing the interaction between the $\mathrm{C} 1$ domain and diacylglycerol, which in turn releases the pseudosubstrate inhibitory domain [24]. In contrast, novel PKCs inherently have much greater affinity for diacylglycerol while binding to the C1 domain [25]. Especially PKC $\theta$ has been linked with diacylglycerol-mediated insulin resistance. PKC- $\theta$ causes serine/threonine phosphorylation of the insulin receptor [26] and of IRS-1 [20,27,28], thereby inhibiting the PI3K/PKB/Akt pathway which subsequently leads to insulin resistance [29]. The key role of diacylglycerol-mediated PKC- $\theta$ activation in the pathogenesis of insulin resistance has been confirmed in human muscle [30]. However, observations linking high-palmitate-induced PKC- $\theta$ activation and inhibition of insulinstimulated GLUT4 translocation in heart and skeletal muscle are scarce. Specifically, it has been reported that in L6-muscle cells made insulin resistant by cytokines (which might play a role in lipid-induced insulin resistance, as detailed below in the subsection Inflammation) from conditioned media [31]. Pharmacological inhibition or silencing of novel PKCs restored insulin-stimulated GLUT4 translocation. However, in palmitate-treated cardiomyocytes that exhibited impaired insulin signaling and insulin-stimulated glucose uptake, diacylglycerol levels were not altered [32]. Taken together, there is conflicting evidence for a possible role of diacylglycerol/PKC- $\theta /$ IRS1 axis in lipid-induced cardiac insulin resistance. These differences could be due to the use of in vitro models versus in vivo, on differences in regulation in heart versus muscle, and on differences in the species of fatty acids supplied.

\subsection{Ceramides}

The intracellular ceramide concentration is elevated in insulin resistant states of skeletal muscles, and therefore it has been claimed as a primary lipid mediator in muscle [33]. Several studies also documented such role of ceramides in cardiac insulin resistance $[34,35]$. Ceramide directly activates PKC $\zeta$, a member of the atypical PKCs, which phosphorylates and inhibits the membraneattachment of Akt/PKB, thereby inhibiting insulin-stimulated glucose uptake by blocking glucose transporter GLUT4 translocation, as well as glycogen synthesis [36,37]. In high fat diet rodent models of insulin resistance, pharmacological inhibition of serine palmitoyltransferase enhances insulin action and insulin-stimulated glucose uptake in both muscle and heart [34,38,39]. Conversely, forced overexpression of sphingosine kinase, which prevents ceramide accumulation, ameliorates insulin resistance in high fat diet-fed mice [40]. Furthermore, cardiac overexpression of FACS, PPAR $\alpha$, PPAR $\gamma$, or FATP has been shown to elevate ceramide levels leading to dilated lipotoxic cardiomyopathy [41-44]. Human studies also confirm that total ceramide levels of skeletal muscle are increased nearly 2-fold in obese insulin-resistant subjects, which is accompanied by a significant reduction in activated Akt/ PKB levels [45]. Finally, myocardial ceramide levels were found to be decreased together with a reversal of insulin resistance in heart failure patients upon implantation of ventricular assist devices [46]. However, in a subset of rodent models of lipid-induced insulin resistance, the association between ceramide levels and insulin resistance was not observed [38].

\subsection{Peroxisome proliferator-activated receptors (PPARs)}

Myocardial fatty acid utilization is controlled, at least in part, at the gene regulatory level, especially during chronic adaptations. Evidence is emerging that nuclear receptors are involved in the development of lipid-induced insulin resistance. The peroxisome proliferator-activated receptors (PPARs) are a family of ligand- activated transcription factors that belong to the nuclear hormone receptor superfamily [47]. PPARs mainly exist in three subtypes: $\alpha$, $\beta / \delta$, and $\gamma$, which are expressed in various tissues in specific ratios and have diverse but overlapping functions in regulating lipid metabolism [48]. Yet, only $\alpha$ and $\beta / \delta$ isoforms regulate lipid metabolism in the heart [49]. PPARs bind fatty acids with a preference for long-chain fatty acids. In addition, numerous fatty acid metabolites, including acyl-CoAs, oxidized fatty acids, eicosanoids, etc., activate PPARs [50].

PPAR $\alpha$ plays a central role in mediating the expression of proteins and enzymes involved in the physiological actions of mitochondrial $\beta$-oxidation of fatty acids, and, specifically, is known to be responsible for upregulating the expression of membraneassociated and cytoplasmic fatty acid transporters [51,52]. Cardiacspecific overexpression of PPAR $\alpha$ in mice results in enhanced fatty acid uptake, triacylglycerol accumulation, and reduced glucoseoxidation [53]. Additional studies indicate that cardiac-specific overexpression of PPAR $\alpha$ in mice leads to cardiac insulin resistance associated with defects in insulin signaling, and subsequently to reduced cardiac function [54]. Interestingly, the absence of CD36 prevented cardiac triacylglycerol accumulation and cardiac dysfunction in the cardiac-restricted overexpression of PPAR $\alpha$ mice, which is associated with increased glucose utilization [55]. Conversely, PPAR $\alpha$-null mice display a decreased capacity of fatty acid metabolism, which likely contributes to dyslipidemia [56,57]. Interestingly, PPAR $\alpha$-null mice are protected from the development of insulin resistance when feeding with a high fat diet [58]. Yet, the beneficial effects of inhibition of fatty acid oxidation via PPAR $\alpha$ downregulation are difficult to comprehend when given that the fatty acid excess would overspill the other lipid metabolic pathways [59]. Likely, the absence of PPAR $\alpha$ reduces the rate of fatty acid oxidation, whereas the utilization of glucose is enhanced despite lower glucose availability in high fat diet-fed mice. Accordingly, PPAR $\alpha$ agonists were proposed and used to restore metabolism in the diabetic heart [59]. However, the PPAR $\alpha$ ligand BM17.0744 did not restore cardiac function in diabetic mice [60]. In a broader sense, the cardio-lipotoxic actions of PPAR $\alpha$ overexpression do not match with the proposed beneficial effects of PPAR $\alpha$ ligands. Furthermore, PPAR $\alpha$ and PPAR $\beta / \delta$ may have overlapping targets and function in the heart. Cardiac-specific $\operatorname{PPAR} \beta / \delta$ overexpressing transgenic mice do not display myocardial lipid accumulation or cardiac dysfunction, even on high fat diet [61]. Taken together, there is much controversy whether PPARs are friends or foes in lipid-induced cardiomyopathy [62].

\subsection{Reactive oxygen species (ROS)}

ROS are generated as by-product of mitochondrial $\beta$-oxidation as a result of some leakage of electrons to oxygen $\left(\mathrm{O}_{2}\right)$ at several sites of the electron transport chain to form superoxide. Antioxidant systems convert superoxide to hydrogen peroxide $\left(\mathrm{H}_{2} \mathrm{O}_{2}\right)$, which is then further degraded into water by catalase. In numerous rodent models of excessive fat feeding and insulin resistance, fatty acid oxidation is increased as a result of the increased fatty acid supply $[19,63,64]$. The resulting increased flux through the electron transport chain is likely to cause increased ROS formation and $\mathrm{H}_{2} \mathrm{O}_{2}$ generation $[64,65]$. Persistent up-regulation of fatty acid oxidation leads to chronically increased ROS formation, which may exhaust the several cellular anti-oxidant systems. Because mitochondrial membranes are especially vulnerable to damage by ROS, progressive mitochondrial damage occurs, ultimately resulting in a decreased fatty acid oxidation capacity. Thus, decreased fatty acid oxidation inevitably follows sustained periods of increased fatty acid oxidation. Therefore, the conflicting literature on whether myocardial fatty acid oxidation is increased $[64,65]$ versus decreased [66-68] in rodent models of insulin resistance might 
be a matter of timing. The decrease in mitochondrial capacity and the resulting decrease in the cardiac energy state could be responsible for cardiac dysfunction in insulin resistant rodents, but this has not yet been fully explored [65]. Furthermore, decreased mitochondrial flux redirects the fatty acids to lipid storage pathways, which may induce a vicious cycle of further accumulation of diacylglycerols, ceramides and triacylglycerols.

While mitochondria are the major source of ROS, also enhanced extra-mitochondrial ROS production might contribute to ROS accumulation in the insulin resistant heart. Indeed, the activity of NADPH oxidase (NOX), the major source of extra-mitochondrial ROS, is elevated in hearts of obese Zucker rats, ob/ob mice, and high fat diet-fed rats [69,70]. Interestingly, pharmacological NOX inhibition reversed cardiac dysfunction in several insulin resistant rodent models $[70,71]$. Thus, cytosolic ROS production may play a role in inducing mitochondrial damage, thereby further impairing mitochondrial function, and directly leading to decreased cardiac contraction [72].

\subsection{Inflammation}

Inflammation has been directly and indirectly associated with lipid-induced insulin resistance and has become a prevailing view to explain the pathogenesis of type 2 diabetes. The fact that inflammation might be one of the contributors to insulin resistance is based on the observation that anti-inflammatory drugs like salicylates reduce hyperglycemia in diabetic patients [73]. Various studies have demonstrated that obesity and high fat diet-feeding causes the recruitment of macrophages, not only to adipose tissue, but also to the heart, concomitant with the production of proinflammatory cytokines, such as tumor necrosis factor- $\alpha$ (TNF- $\alpha$ ) and interleukin-6 (IL-6) [74,75]. Additionally, cardiomyocytes, like many other mammalian cells, produce these cytokines upon direct exposure to fatty acids via fatty acid binding to the pattern-recognition receptor, Toll-like receptor-4 (TLR4) [76]. TLRs are essential for mounting inflammatory responses associated with innate immunity, but are also activated in the presence of chronically activated fatty acid concentrations [77]. TLR activation, through MyD88, results in activation of IKB kinase (IKK), movement of the nuclear factor- $\kappa \mathrm{B}$ to the nucleus leading to cytokine production $[78,79]$. These cytokines, TNF- $\alpha$ and IL- 6 , on their turn, through binding to their receptors in an autocrine amplification loop, induce Ser-phosphorylation of IRS via suppressor of cytokine signaling-3 (SOCS-3) and c-Jun $N$-terminal kinase (JNK) [80]. Moreover, fatty acid activation of TLR4 also directly activates JNK and PKCs, and thereby induce Ser/Thr-phosphorylation of IRS [81]. As mentioned in Section 3, this Ser/Thr-phosphorylation of IRS will lead to insulin resistance.

Interestingly, lipid-induced insulin resistance in muscle mediated by TLR4 requires the generation of ceramide [82]. TLR4-stimulated ceramide generation is postulated to be mediated by IKK activation and the synthesis of enzymes in the ceramide synthesis pathway (e.g., serine palmitoyltransferase). Hence, the inflammatory pathways have a closely intertwined relationship with the lipid-induced signaling pathways to induce insulin resistance [83].

\section{Insulin resistance and subsequent cardiac contractile dysfunction}

Both rodent models and clinical studies support that lipid-induced insulin resistance eventually precipitates into cardiac contractile dysfunction [84]. Also in vitro, in cardiomyocyte cultures exposed to excess fatty acids, the onset of insulin resistance occurred in association with a marked decrease in contractile activity of the cardiomyocytes [32]. However, the relationship between insulin resistance and cardiac contractile function remains unclear. Potential mechanisms may include abnormal intracellular $\mathrm{Ca}^{2+}$ dynamics or myosin isozyme switch, as discussed below [85-87].

\section{1. $\mathrm{Ca}^{2+}$ dynamics}

Myocardial contractile force is dependent on the intracellular $\mathrm{Ca}^{2+}$ concentration and its regulation, because both the release and the re-uptake of intracellular $\mathrm{Ca}^{2+}$ are necessary to maintain the normal systolic and diastolic functions of the heart. Therefore, changing the availability of $\mathrm{Ca}^{2+}$ to the myofilaments or shifting the responsiveness of the myofilaments to activation by intracellular $\mathrm{Ca}^{2+}$ may alter cardiac contractile function. It has been observed that in the failing heart the density of $\mathrm{Ca}^{2+}$ uptake sites on the sarcoplasmic reticulum is decreased, and that $\mathrm{Ca}^{2+}$ release is impaired. Thus, abnormal handling of intracellular $\mathrm{Ca}^{2+}$ may be a primary cause of contractile dysfunction $[88,89]$. Sarcoplasmic reticulum $\mathrm{Ca}^{2+}$ storage is possibly reduced in diabetic cardiomyocytes, yet the mechanism remains unknown [90]. In cardiomyocytes from diet-induced insulin resistant rats, decreased SERCA activity contributed to contractile dysfunction of insulin resistant cardiomyocytes [91]. Furthermore, altered cardiomyocyte $\mathrm{Ca}^{2+}$ handling appears to gain importance in the later stages of diabetes [91].

\subsection{Myosin isozyme switch}

ATP hydrolysis by myofibrillar and myosin ATPase is the ratelimiting step in of cardiac contraction. It is generally accepted that reduced myofibrillar ATPase activity is associated with contractile dysfunction during the onset of insulin resistance [84]. The underlying mechanism for decreased activity of this ATPase is a switch in myosin isozyme expression, i.e., from myosin heavy chain (MHC)- $\alpha / \alpha$ homodimer to the $\beta / \beta$ homodimer $[92,93]$. This increased $\beta$-MHC expression slows actin-myosin kinetics, and contributes to contractile dysfunction of the insulin resistant rodent heart [94]. The shift to the less efficient $\beta$-MHC in the insulin resistant heart also causes a marked reduction in formation and dissociation of actin-myosin cross-bridges [94]. Because this crossbridge cycling is important in force development, cross-bridge dysregulation could contribute to contractile dysfunction.

Several other contractile derangements could contribute to contractile dysfunction in the insulin resistant heart, such as changes in accessory proteins of the thick filament, in the actin thin filament or in the extra-sarcomeric cytoskeleton, but some of these changes are still controversial and need further investigation [84]. Taken together, the exact mechanism how cardiac insulin resistance causes contractile dysfunction is not known yet.

Interestingly, rodent studies indicate that contractile dysfunction of cardiomyocytes from insulin resistant rats can be prevented by metformin treatment [85]. Metformin likely does not directly impact on the heart, but will act in an indirect manner via reducing hepatic gluconeogenesis. Moreover, metformin treatment normalizes mechanical indexes, suggesting that cardiac contractile dysfunction can be prevented by inhibition of insulin resistance [85].

\section{Impairment of cardiac contractile function by lipids independently from insulin resistance}

Although it is evident that lipid excess over time causes cardiac insulin resistance, and that cardiac insulin resistance may further progress into contractile dysfunction, there are also several indications that lipids can worsen cardiac function independently of 
insulin resistance. This line of evidence is derived from studies with transgenic mouse models with altered contents of lipid metabolizing enzymes, i.e., allowing for separation of lipid accumulation from insulin resistance. In mice with cardiac overexpression of DGAT, the rate limiting enzyme in the triacylglycerol synthesis, diacylglycerol levels were unchanged, while triacylglycerol levels were increased. These mice exhibited no metabolic derangements including changes in insulin sensitivity, but yet displayed diastolic dysfunction and cardiomyopathy [95]. However, these findings contrast with another study, in which cardiospecific DGAT overexpression did not lead to cardiomyopathy, but rather offered cardio-protection in a mouse model of cardiac lipid overload [96]. Additionally, ATGL knockout mice were studied to investigate the impact of triacylglycerol accumulation on cardiac function, and were found to exhibit severe systolic and diastolic dysfunction [97]. Yet, ATGL-driven lipid accumulation rather increased insulin sensitivity in heart and liver [98]. This cardiotoxic action of ATGL overexpression was attributed to diminished PPAR $\alpha$ signaling [97], but this has been disputed [99]. Vice versa, cardio-specific ATGL overexpression prevents cardiac triacylglycerol accumulation and preserves cardiac function in mice on high fat diet, but does not alter insulin sensitivity [100]. Hence, these studies suggest that triacylglycerols, considered as an "inert" lipid species (i.e., without signaling actions), would induce cardiomyopathy via a different route. Also other lipid species, such as ceramides and acyl-carnitines might induce contractile dysfunction independently of insulin resistance, as discussed below. Taken together, this implies that therapeutic treatment strategies to combat lipid-induced cardiomyopathy via restoration of insulin signaling may not always be effective. Below, we will discuss some possible mechanisms of triacylglycerol-mediated cardiomyopathy independent of insulin resistance.

\subsection{Loss of caveolin-3}

A possible novel mechanism for lipid-induced cardiac contractile dysfunction includes the loss of caveolin-3 during cardiac lipid oversupply [101]. Caveolins are the defining protein constituents of caveolae, which are responsible for the invagination of the plasma membrane. Three members have been identified, and caveolin-3 is the predominant isoform in muscle and heart. Caveolins play an important role in endocytosis, lipid trafficking, and signal transduction [102]. Caveolin-3 is also present in T-tubules and is associated with the development of the T-tubule system. Concordingly, caveolin-3 null mice have abnormal T-tubuli and display a phenotype similar to muscular dystrophy [103,104]. Loss of cardiac caveolin-3 or caveolin-3 mutations have been proven to induce hypertrophy that eventually leads to dilated cardiomyopathy [105-107]. High fat diet induces a loss of caveolin-3 together with contractile dysfunction [101]. This high fat diet-induced cardiomyopathy resembles the cardiomyopathy in the caveolin-3 null mice [104]. The mechanism is related with the downregulation of RyR in cardiomyocytes following the loss of T-tubule structure, and is expected to cause impaired calcium handling and contractile dysfunction. This novel finding suggests that the expression and intracellular localization of caveolin-3 is crucial in heart failure and could be a potential therapeutic target for the improvement of lipid-induced cardiac contractile dysfunction. Yet caveolin-3 deletion also impairs insulin signaling, as caveolae are important for functioning of insulin receptors [108]. Hence, it is difficult to study the role defective T-tubuli in the development of cardiac contractile dysfunction in caveolin-3 null mice separately from changes in insulin signaling.

\subsection{Acyl-carnitines}

During lipid overload, acyl-carnitines levels rise due to the high rates of fatty acid oxidation exceeding the metabolic flux through the tricaboxylic acid cycle [109]. Several mechanisms appear responsible for the pro-arrhythmic effects of acyl-carnitines. First, reduction of the single-channel conductance of the inward-going rectifier $\mathrm{K}^{+}$current may produce automatic action potential discharges resulting in ventricular tachycardia. Second, the decrease of the excitatory $\mathrm{Na}^{+}$current could generate conduction anomalies and result in re-entry [110]. Finally, amphipathic metabolites may impair gap-junction channels [111]. The increased risk of arrhythmias of the lipid-overloaded heart might contribute to the pathogenesis of cardiomyopathy.

\subsection{Apoptosis}

Apoptosis in the heart inevitably leads to decreased cardiac muscle mass, which may therefore contribute to loss of cardiac contractility. Lipids are known to induce apoptosis [112], and lipidinduced apoptosis contributes to the pleiotropy of cellular maladaptive actions of lipids, summarized in the term lipotoxicity (see Section 1). Lipid-induced apoptosis is generally associated with excess ceramides [112-114]. Ceramides have been reported to increase expression of inducible nitric oxide synthase (iNOS), thereby increasing NO production, and consequently ROS production and ROS-dependent apoptosis [112]. Ceramides also activate JNK, which interacts with Bax in the mitochondrial membrane, causing release of cytochrome $\mathrm{c}$ and activation of the caspase cascade as part of the apoptotic pathway [113]. Given that these ceramide actions overlap with the effects of ceramides on inhibition of insulin signaling and activation of ROS and inflammation, it is likely that apoptosis induced by excess lipids/ ceramides cannot be seen entirely independent of the onset of insulin resistance.

\subsection{Stereological hindrance}

Triacylglycerols stored in lipid droplets might directly impair cardiac contractility. As shown in electron-microscopical pictures from skeletal muscle of obese Zucker rats (a rat model of lipid oversupply), excess lipids primarily accumulate within myocytes in the form of lipid droplets in the intra-myofibrillar regions [115]. This interspersion of myofibrils with large lipid droplets might also be present in cardiomyocytes from rodent models of lipid oversupply. Perhaps, a simple explanation of lipid-induced contractile dysfunction could include that lipid droplets impair proper contraction mechanics just by spatial hindrance.

\section{Concluding remarks}

The putative mechanisms leading to lipid-induced insulin resistance and contractile dysfunction in the heart are manifold and together form a complex entity. Intentionally, we discussed these putative mechanisms separately, as summarized in the flow chart (Fig. 3). However, when focusing first on the causes of insulin resistance (Fig. 3, orange boxes), most of the concerned pathways are known to interact. For instance, sustained ROS production as a result of chronically increased fatty acid oxidation results in mitochondrial damage, which inevitably merges into a next phase of decreased fatty acid oxidation. This would then divert the incoming lipids increasingly into lipid storage pathways with the accompanying rise of diacylglycerols and ceramides. In this way an amplification loop is initiated. Another example relates to the interaction between inflammation, ROS and ceramides, where lipid- 


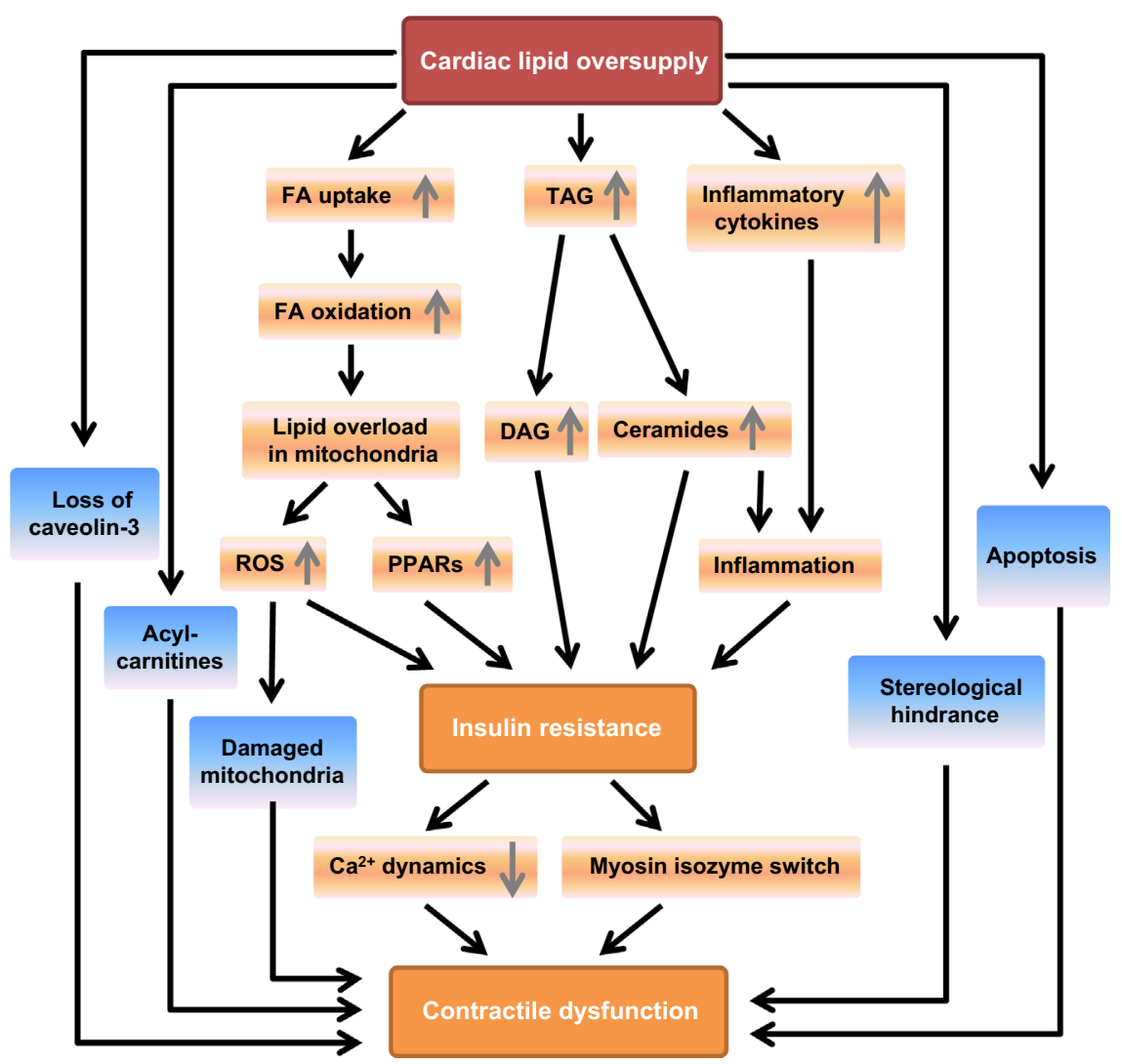

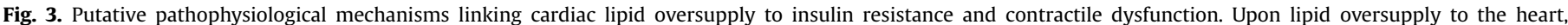

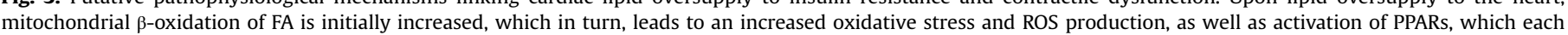

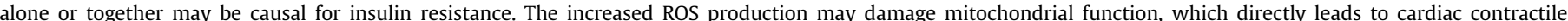

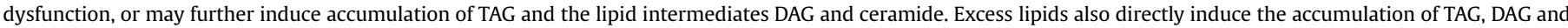

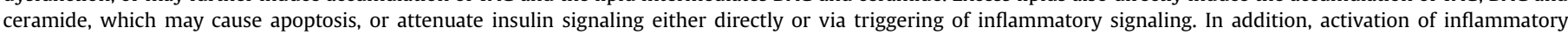

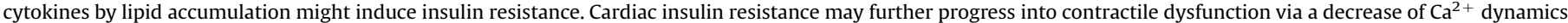

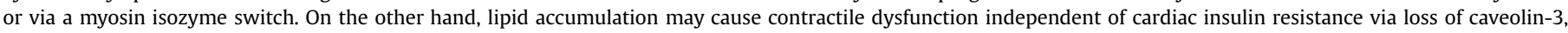
increased levels of acyl-carnitines, damaged mitochondrial function, apoptosis, or stereological hindrance.

induced TLR4-dependent inflammatory signaling via the IKK/NF$\kappa \mathrm{B}$ route (and/or via TNF- $\alpha$ ) leads to JNK and PKC activation, ultimately causing inhibition of insulin signaling by serine phosphorylation of IRS [81]. Such inflammatory mechanism of decreased insulin sensitivity may thus amplify the direct effects of lipid intermediates (i.e., ceramides and diacylglycerols) on inhibition of insulin signaling. Furthermore, ROS [116] and ceramides [113] have been shown to activate the IKK/NF- $K B$ axis of inflammation signaling. Hence, ROS may impact on insulin resistance via mitochondrial damage and inflammation (and perhaps also other processes), while ceramides may induce insulin resistance via Akt inhibition, ROS generation and by activation of pro-inflammatory signaling.

The picture gets even more complicated when also considering the insulin resistance-independent mediators (as mentioned in Section 6) in the pathogenesis of lipid-induced cardiomyopathy (Fig. 3, blue boxes). This especially applies to apoptosis, which can be induced by either ROS, inflammation and/or ceramides (being classified in this review as insulin-dependent mediators of lipidinduced contractile dysfunction) via activation of the caspase pathway, more or less independently of insulin resistance $[113,114]$, and thereby further contribute to contractile dysfunction. In contrast, triacylglycerols (via stereological hindrance) and acyl-carnitines (via their pro-arrhythmogenic actions) appear to have little cross-talk with other mediators, and thus may contribute rather independently to decreased contractility in the lipid-overloaded heart.
Taken together, the mediators of lipid-induced contractile dysfunction discussed here interact in a complicated and partly overlapping manner, while various amplifying loops may contribute to further complexity. Several of these lipid-induced derangements were originally established in transgenic and dietinduced rodent models, and have been verified in humans [30,117]. Further progress in this field is needed to serve the identification of new therapeutic targets and treatment strategies in order to combat lipid-induced cardiomyopathy. Yet, the most obvious strategy for humans is to abstain from chronic lipid overconsumption, which would prevent the onset of this major cause of cardiomyopathy.

\section{Acknowledgements}

Y. Liu was supported by a grant from the China Scholarship Council. D. Neumann is the recipient of a VIDI-Innovational Research grant from the Netherlands Organization for Scientific Research (NWO-ALW).

\section{References}

[1] J.S. Ingwall, Energy metabolism in heart failure and remodelling, Cardiovasc. Res. 81 (2009) 412-419.

[2] W.C. Stanley, F.A. Recchia, G.D. Lopaschuk, Myocardial substrate metabolism in the normal and failing heart, Physiol. Rev. 85 (2005) 1093-1129. 
[3] T.R. Koves, J.R. Ussher, R.C. Noland, D. Slentz, M. Mosedale, O. Ilkayeva, J. Bain, R. Stevens, J.R. Dyck, C.B. Newgard, G.D. Lopaschuk, D.M. Muoio, Mitochondrial overload and incomplete fatty acid oxidation contribute to skeletal muscle insulin resistance, Cell Metab. 7 (2008) 45-56.

[4] J.F. Glatz, J.J. Luiken, A. Bonen, Membrane fatty acid transporters as regulators of lipid metabolism: implications for metabolic disease, Physiol. Rev. 90 (2010) 367-417.

[5] D.D. Habets, W.A. Coumans, P.J. Voshol, M.A. den Boer, M. Febbraio, A. Bonen, J.F. Glatz, J.J. Luiken, AMPK-mediated increase in myocardial long-chain fatty acid uptake critically depends on sarcolemmal CD36, Biochem. Biophys. Res. Commun. 355 (2007) 204-210.

[6] N.A. Abumrad, CD36 may determine our desire for dietary fats, J. Clin. Investig. 115 (2005) 2965-2967.

[7] L.K. Steinbusch, R.W. Schwenk, D.M. Ouwens, M. Diamant, J.F. Glatz, J. J. Luiken, Subcellular trafficking of the substrate transporters GLUT4 and CD36 in cardiomyocytes, Cell. Mol. Life Sci. 68 (2011) 2525-2538.

[8] H.K. Karlsson, J.R. Zierath, S. Kane, A. Krook, G.E. Lienhard, H. WallbergHenriksson, Insulin-stimulated phosphorylation of the Akt substrate AS160 is impaired in skeletal muscle of type 2 diabetic subjects, Diabetes 54 (2005) 1692-1697.

[9] J.D. McGarry, G.F. Leatherman, D.W. Foster, Carnitine palmitoyltransferase I. The site of inhibition of hepatic fatty acid oxidation by malonyl-CoA, J. Biol. Chem. 253 (1978) 4128-4136.

[10] J.D. McGarry, N.F. Brown, The mitochondrial carnitine palmitoyltransferase system. From concept to molecular analysis, Eur. J. Biochem. 244 (1997) 1-14.

[11] K. Jaworski, E. Sarkadi-Nagy, R.E. Duncan, M. Ahmadian, H.S. Sul, Regulation of triglyceride metabolism. IV. Hormonal regulation of lipolysis in adipose tissue, Am. J. Physiol. Gastrointest. Liver Physiol. 293 (2007) G1-G4.

[12] L. Bertrand, S. Horman, C. Beauloye, J.L. Vanoverschelde, Insulin signalling in the heart, Cardiovasc. Res. 79 (2008) 238-248.

[13] B. DeBosch, N. Sambandam, C. Weinheimer, M. Courtois, A.J. Muslin, Akt2 regulates cardiac metabolism and cardiomyocyte survival, J. Biol. Chem. 281 (2006) 32841-32851.

[14] K.M. Geraghty, S. Chen, J.E. Harthill, A.F. Ibrahim, R. Toth, N.A. Morrice, F. Vandermoere, G.B. Moorhead, D.G. Hardie, C. MacKintosh, Regulation of multisite phosphorylation and 14-3-3 binding of AS160 in response to IGF-1, EGF, PMA and AICAR, Biochem. J. 407 (2007) 231-241.

[15] S. Chen, D.H. Wasserman, C. MacKintosh, K. Sakamoto, Mice with AS160/ TBC1D4-Thr649Ala knockin mutation are glucose intolerant with reduced insulin sensitivity and altered GLUT4 trafficking, Cell Metab. 13 (2011) 68-79.

[16] M.L. Standaert, G. Bandyopadhyay, L. Perez, D. Price, L. Galloway, A. Poklepovic, M.P. Sajan, V. Cenni, A. Sirri, J. Moscat, A. Toker, R.V. Farese, Insulin activates protein kinases C-zeta and C-lambda by an autophosphorylation-dependent mechanism and stimulates their translocation to GLUT4 vesicles and other membrane fractions in rat adipocytes, J. Biol. Chem. 274 (1999) 25308-25316.

[17] D.D. Habets, J.J. Luiken, M. Ouwens, W.A. Coumans, M. Vergouwe, S. J. Maarbjerg, M. Leitges, A. Bonen, E.A. Richter, J.F. Glatz, Involvement of atypical protein kinase $C$ in the regulation of cardiac glucose and long-chain fatty acid uptake, Front Physiol. 3 (2012) 361.

[18] A. Bonen, S.S. Jain, L.A. Snook, X.X. Han, Y. Yoshida, K.H. Buddo, J.S. Lally, E D. Pask, S. Paglialunga, M.S. Beaudoin, J.F. Glatz, J.J. Luiken, E. Harasim, D. C. Wright, A. Chabowski, G.P. Holloway, Extremely rapid increase in fatty acid transport and intramyocellular lipid accumulation but markedly delayed insulin resistance after high fat feeding in rats, Diabetologia 58 (2015) 2381-2391.

[19] D.M. Ouwens, M. Diamant, M. Fodor, D.D. Habets, M.M. Pelsers, M. El Hasnaoui, Z.C. Dang, C.E. van den Brom, R. Vlasblom, A. Rietdijk, C. Boer, S. L. Coort, J.F. Glatz, J.J. Luiken, Cardiac contractile dysfunction in insulin-resistant rats fed a high-fat diet is associated with elevated CD36-mediated fatty acid uptake and esterification, Diabetologia 50 (2007) 1938-1948.

[20] C. Yu, Y. Chen, G.W. Cline, D. Zhang, H. Zong, Y. Wang, R. Bergeron, J.K. Kim, S. W. Cushman, G.J. Cooney, B. Atcheson, M.F. White, E.W. Kraegen, G. I. Shulman, Mechanism by which fatty acids inhibit insulin activation of insulin receptor substrate-1 (IRS-1)-associated phosphatidylinositol 3-kinase activity in muscle, J. Biol. Chem. 277 (2002) 50230-50236.

[21] W.L. Holland, J.T. Brozinick, L.P. Wang, E.D. Hawkins, K.M. Sargent, Y. Liu, K. Narra, K.L. Hoehn, T.A. Knotts, A. Siesky, D.H. Nelson, S.K. Karathanasis, G. K. Fontenot, M.J. Birnbaum, S.A. Summers, Inhibition of ceramide synthesis ameliorates glucocorticoid-, saturated-fat-, and obesity-induced insulin resistance, Cell Metab. 5 (2007) 167-179.

[22] M. Bronfman, M.N. Morales, A. Orellana, Diacylglycerol activation of protein kinase $C$ is modulated by long-chain acyl-CoA, Biochem. Biophys. Res. Commun. 152 (1988) 987-992.

[23] Y. Nishizuka, Protein kinase C and lipid signaling for sustained cellular responses, FASEB J. 9 (1995) 484-496.

[24] A.C. Newton, Protein kinase C. Seeing two domains, Curr. Biol. 5 (1995) 973-976.

[25] D.R. Dries, L.L. Gallegos, A.C. Newton, A single residue in the C1 domain sensitizes novel protein kinase $\mathrm{C}$ isoforms to cellular diacylglycerol production, J. Biol. Chem. 282 (2007) 826-830.

[26] S.I. Itani, Q. Zhou, W.J. Pories, K.G. MacDonald, G.L. Dohm, Involvement of protein kinase $C$ in human skeletal muscle insulin resistance and obesity, Diabetes 49 (2000) 1353-1358.

[27] V.T. Samuel, G.I. Shulman, Mechanisms for insulin resistance: common threads and missing links, Cell 148 (2012) 852-871.
[28] L.V. Ravichandran, D.L. Esposito, J. Chen, M.J. Quon, Protein kinase C-zeta phosphorylates insulin receptor substrate- 1 and impairs its ability to activate phosphatidylinositol 3-kinase in response to insulin, J. Biol. Chem. 276 (2001) 3543-3549.

[29] D.B. Savage, K.F. Petersen, G.I. Shulman, Mechanisms of insulin resistance in humans and possible links with inflammation, Hypertension 45 (2005) 828-833.

[30] J. Szendroedi, T. Yoshimura, E. Phielix, C. Koliaki, M. Marcucci, D. Zhang, T. Jelenik, J. Muller, C. Herder, P. Nowotny, G.I. Shulman, M. Roden, Role of diacylglycerol activation of PKCtheta in lipid-induced muscle insulin resistance in humans, Proc. Natl. Acad. Sci. USA 111 (2014) 9597-9602.

[31] G. Kewalramani, L.N. Fink, F. Asadi, A. Klip, Palmitate-activated macrophages confer insulin resistance to muscle cells by a mechanism involving protein kinase C theta and epsilon, PLoS One 6 (2011) e26947.

[32] Y. Angin, L.K. Steinbusch, P.J. Simons, S. Greulich, N.T. Hoebers, K. Douma, M. A. van Zandvoort, W.A. Coumans, W. Wijnen, M. Diamant, D.M. Ouwens, J. F. Glatz, J.J. Luiken, CD36 inhibition prevents lipid accumulation and contractile dysfunction in rat cardiomyocytes, Biochem. J. 448 (2012) 43-53.

[33] M.J. Watt, N. Dzamko, W.G. Thomas, S. Rose-John, M. Ernst, D. Carling, B. E. Kemp, M.A. Febbraio, G.R. Steinberg, CNTF reverses obesity-induced insulin resistance by activating skeletal muscle AMPK, Nat. Med. 12 (2006) 541-548.

[34] J.R. Ussher, C.D. Folmes, W. Keung, N. Fillmore, J.S. Jaswal, V.J. Cadete, D. L. Beker, V.H. Lam, L. Zhang, G.D. Lopaschuk, Inhibition of serine palmitoyl transferase I reduces cardiac ceramide levels and increases glycolysis rates following diet-induced insulin resistance, PLoS One 7 (2012) e37703.

[35] E. Ramirez, M. Klett-Mingo, S. Ares-Carrasco, B. Picatoste, A. Ferrarini, F J. Ruperez, A. Caro-Vadillo, C. Barbas, J. Egido, J. Tunon, O. Lorenzo, Eplerenone attenuated cardiac steatosis, apoptosis and diastolic dysfunction in experimental type-II diabetes, Cardiovasc. Diabetol. 12 (2013) 172.

[36] E. Hajduch, A. Balendran, I.H. Batty, G.J. Litherland, A.S. Blair, C.P. Downes, H. S. Hundal, Ceramide impairs the insulin-dependent membrane recruitment of protein kinase B leading to a loss in downstream signalling in L6 skeletal muscle cells, Diabetologia 44 (2001) 173-183.

[37] S. Stratford, D.B. DeWald, S.A. Summers, Ceramide dissociates 3'-phosphoinositide production from pleckstrin homology domain translocation, Biochem. J. 354 (2001) 359-368.

[38] W.L. Holland, S.A. Summers, Sphingolipids, insulin resistance, and metabolic disease: new insights from in vivo manipulation of sphingolipid metabolism, Endocr. Rev. 29 (2008) 381-402.

[39] G. Frangioudakis, J. Garrard, K. Raddatz, J.L. Nadler, T.W. Mitchell, C. SchmitzPeiffer, Saturated- and n-6 polyunsaturated-fat diets each induce ceramide accumulation in mouse skeletal muscle: reversal and improvement of glucose tolerance by lipid metabolism inhibitors, Endocrinology 151 (2010) 4187-4196.

[40] C.R. Bruce, S. Risis, J.R. Babb, C. Yang, G.M. Kowalski, A. Selathurai, R.S. LeeYoung, J.M. Weir, K. Yoshioka, Y. Takuwa, P.J. Meikle, S.M. Pitson, M. A. Febbraio, Overexpression of sphingosine kinase 1 prevents ceramide ac cumulation and ameliorates muscle insulin resistance in high-fat diet-fed mice, Diabetes 61 (2012) 3148-3155.

[41] H.C. Chiu, A. Kovacs, D.A. Ford, F.F. Hsu, R. Garcia, P. Herrero, J.E. Saffitz, J. E. Schaffer, A novel mouse model of lipotoxic cardiomyopathy, J. Clin. Investig. 107 (2001) 813-822.

[42] B.N. Finck, X. Han, M. Courtois, F. Aimond, J.M. Nerbonne, A. Kovacs, R. W. Gross, D.P. Kelly, A critical role for PPARalpha-mediated lipotoxicity in the pathogenesis of diabetic cardiomyopathy: modulation by dietary fat content, Proc. Natl. Acad. Sci. USA 100 (2003) 1226-1231.

[43] N.H. Son, T.S. Park, H. Yamashita, M. Yokoyama, L.A. Huggins, K. Okajima, S. Homma, M.J. Szabolcs, L.S. Huang, I.J. Goldberg, Cardiomyocyte expression of PPARgamma leads to cardiac dysfunction in mice, J. Clin. Investig. 117 (2007) 2791-2801.

[44] H.C. Chiu, A. Kovacs, R.M. Blanton, X. Han, M. Courtois, C.J. Weinheimer, K. A. Yamada, S. Brunet, H. Xu, J.M. Nerbonne, M.J. Welch, N.M. Fettig, T.L. Sharp, N. Sambandam, K.M. Olson, D.S. Ory, J.E. Schaffer, Transgenic expression of fatty acid transport protein 1 in the heart causes lipotoxic cardiomyopathy, Circ. Res. 96 (2005) 225-233.

[45] J.M. Adams 2nd, T. Pratipanawatr, R. Berria, E. Wang, R.A. DeFronzo, M. C. Sullards, L.J. Mandarino, Ceramide content is increased in skeletal muscle from obese insulin-resistant humans, Diabetes 53 (2004) 25-31.

[46] A. Chokshi, K. Drosatos, F.H. Cheema, R. Ji, T. Khawaja, S. Yu, T. Kato, R. Khan, H. Takayama, R. Knoll, H. Milting, C.S. Chung, U. Jorde, Y. Naka, D.M. Mancini, I. J. Goldberg, P.C. Schulze, Ventricular assist device implantation corrects myocardial lipotoxicity, reverses insulin resistance, and normalizes cardiac metabolism in patients with advanced heart failure, Circulation 125 (2012) 2844-2853.

[47] B.M. Spiegelman, J.S. Flier, Adipogenesis and obesity: rounding out the big picture, Cell 87 (1996) 377-389.

[48] S. Tyagi, P. Gupta, A.S. Saini, C. Kaushal, S. Sharma, The peroxisome proliferator-activated receptor: a family of nuclear receptors role in various diseases, J. Adv. Pharm. Technol. Res. 2 (2011) 236-240.

[49] A.J. Gilde, K.A. van der Lee, P.H. Willemsen, G. Chinetti, F.R. van der Leij, G. J. van der Vusse, B. Staels, M. van Bilsen, Peroxisome proliferator-activated receptor (PPAR) alpha and PPARbeta/delta, but not PPARgamma, modulate the expression of genes involved in cardiac lipid metabolism, Circ. Res. 92 (2003) 518-524.

[50] A. Georgiadi, S. Kersten, Mechanisms of gene regulation by fatty acids, Adv. Nutr. 3 (2012) 127-134. 
[51] L. Cheng, G. Ding, Q. Qin, Y. Huang, W. Lewis, N. He, R.M. Evans, M. D. Schneider, F.A. Brako, Y. Xiao, Y.E. Chen, Q. Yang, Cardiomyocyte-restricted peroxisome proliferator-activated receptor-delta deletion perturbs myocardial fatty acid oxidation and leads to cardiomyopathy, Nat. Med. 10 (2004) 1245-1250.

[52] M. Wierzbicki, A. Chabowski, M. Zendzian-Piotrowska, J. Gorski, Differential effects of in vivo PPAR alpha and gamma activation on fatty acid transport proteins expression and lipid content in rat liver, J. Physiol. Pharmacol. 60 (2009) 99-106.

[53] B.N. Finck, J.J. Lehman, T.C. Leone, M.J. Welch, M.J. Bennett, A. Kovacs, X. Han, R.W. Gross, R. Kozak, G.D. Lopaschuk, D.P. Kelly, The cardiac phenotype induced by PPARalpha overexpression mimics that caused by diabetes mellitus, J. Clin. Investig. 109 (2002) 121-130.

[54] S.Y. Park, Y.R. Cho, B.N. Finck, H.J. Kim, T. Higashimori, E.G. Hong, M.K. Lee, C. Danton, S. Deshmukh, G.W. Cline, J.J. Wu, A.M. Bennett, B. Rothermel, A. Kalinowski, K.S. Russell, Y.B. Kim, D.P. Kelly, J.K. Kim, Cardiac-specific overexpression of peroxisome proliferator-activated receptor-alpha causes insulin resistance in heart and liver, Diabetes 54 (2005) 2514-2524.

[55] J. Yang, N. Sambandam, X. Han, R.W. Gross, M. Courtois, A. Kovacs, M. Febbraio, B.N. Finck, D.P. Kelly, CD36 deficiency rescues lipotoxic cardiomyopathy, Circ. Res. 100 (2007) 1208-1217.

[56] F. Djouadi, C.J. Weinheimer, J.E. Saffitz, C. Pitchford, J. Bastin, F.J. Gonzalez, D. P. Kelly, A gender-related defect in lipid metabolism and glucose homeostasis in peroxisome proliferator- activated receptor alpha- deficient mice, J. Clin. Investig. 102 (1998) 1083-1091.

[57] J.M. Peters, N. Hennuyer, B. Staels, J.C. Fruchart, C. Fievet, F.J. Gonzalez, J. Auwerx, Alterations in lipoprotein metabolism in peroxisome proliferatoractivated receptor alpha-deficient mice, J. Biol. Chem. 272 (1997) 27307-27312.

[58] M. Guerre-Millo, C. Rouault, P. Poulain, J. Andre, V. Poitout, J.M. Peters, F. J. Gonzalez, J.C. Fruchart, G. Reach, B. Staels, PPAR-alpha-null mice are protected from high-fat diet-induced insulin resistance, Diabetes 50 (2001) 2809-2814.

[59] T.I. Lee, Y.H. Kao, Y.C. Chen, J.H. Huang, F.C. Hsiao, Y.J. Chen, Peroxisome proliferator-activated receptors modulate cardiac dysfunction in diabetic cardiomyopathy, Diabetes Res. Clin. Pract. 100 (2013) 330-339.

[60] E. Aasum, M. Cooper, D.L. Severson, T.S. Larsen, Effect of BM 17.0744, a PPARalpha ligand, on the metabolism of perfused hearts from control and diabetic mice, Can. J. Physiol. Pharmacol. 83 (2005) 183-190.

[61] E.M. Burkart, N. Sambandam, X. Han, R.W. Gross, M. Courtois, C.M. Gierasch, K. Shoghi, M.J. Welch, D.P. Kelly, Nuclear receptors PPARbeta/delta and PPARalpha direct distinct metabolic regulatory programs in the mouse heart, J. Clin. Investig. 117 (2007) 3930-3939.

[62] C.J. Pol, M. Lieu, K. Drosatos, PPARs: protectors or opponents of myocardial function? PPAR Res. 2015 (2015) 835985.

[63] S.L. Coort, D.M. Hasselbaink, D.P. Koonen, J. Willems, W.A. Coumans, A. Chabowski, G.J. van der Vusse, A. Bonen, J.F. Glatz, J.J. Luiken, Enhanced sarcolemmal FAT/CD36 content and triacylglycerol storage in cardiac myocytes from obese zucker rats, Diabetes 53 (2004) 1655-1663.

[64] S. Boudina, H. Bugger, S. Sena, B.T. O'Neill, V.G. Zaha, O. Ilkun, J.J. Wright, P. K. Mazumder, E. Palfreyman, T.J. Tidwell, H. Theobald, O. Khalimonchuk, B. Wayment, X. Sheng, K.J. Rodnick, R. Centini, D. Chen, S.E. Litwin, B. E. Weimer, E.D. Abel, Contribution of impaired myocardial insulin signaling to mitochondrial dysfunction and oxidative stress in the heart, Circulation 119 (2009) 1272-1283.

[65] O. Ilkun, S. Boudina, Cardiac dysfunction and oxidative stress in the metabolic syndrome: an update on antioxidant therapies, Curr. Pharm. Des. 19 (2013) 4806-4817.

[66] H. Bugger, E.D. Abel, Molecular mechanisms for myocardial mitochondrial dysfunction in the metabolic syndrome, Clin. Sci. Lond. 114 (2008) 195-210.

[67] M.A. Abdul-Ghani, R.A. DeFronzo, Pathogenesis of insulin resistance in skeletal muscle, J. Biomed. Biotechnol. 2010 (2010) 476279.

[68] B.G. Teodoro, F.G. Baraldi, I.H. Sampaio, L.H. Bomfim, A.L. Queiroz, M. A. Passos, E.M. Carneiro, L.C. Alberici, R. Gomis, F.G. Amaral, J. Cipolla-Neto, M.B. Araujo, T. Lima, S. Akira Uyemura, L.R. Silveira, E. Vieira, Melatonin prevents mitochondrial dysfunction and insulin resistance in rat skeletal muscle, J. Pineal Res. 57 (2014) 155-167.

[69] S. Serpillon, B.C. Floyd, R.S. Gupte, S. George, M. Kozicky, V. Neito, F. Recchia, W. Stanley, M.S. Wolin, S.A. Gupte, Superoxide production by NAD(P)H oxidase and mitochondria is increased in genetically obese and hyperglycemic rat heart and aorta before the development of cardiac dysfunction. The role of glucose-6-phosphate dehydrogenase-derived NADPH, Am. J. Physiol. Heart Circ. Physiol. 297 (2009) H153-H162.

[70] S.Y. Li, X. Yang, A.F. Ceylan-Isik, M. Du, N. Sreejayan, J. Ren, Cardiac contractile dysfunction in Lep/Lep obesity is accompanied by NADPH oxidase activation, oxidative modification of sarco(endo)plasmic reticulum $\mathrm{Ca}^{2+}$-ATPase and myosin heavy chain isozyme switch, Diabetologia 49 (2006) 1434-1446.

[71] N.D. Roe, D.P. Thomas, J. Ren, Inhibition of NADPH oxidase alleviates experimental diabetes-induced myocardial contractile dysfunction, Diabetes Obes. Metab. 13 (2011) 465-473.

[72] J.G. Duncan, Mitochondrial dysfunction in diabetic cardiomyopathy, Biochim. Biophys. Acta 1813 (2011) 1351-1359.

[73] J. Reid, A.I. Macdougall, M.M. Andrews, Aspirin and diabetes mellitus, Br. Med. J. 2 (1957) 1071-1074.

[74] H.J. Ko, Z. Zhang, D.Y. Jung, J.Y. Jun, Z. Ma, K.E. Jones, S.Y. Chan, J.K. Kim, Nutrient stress activates inflammation and reduces glucose metabolism by suppressing AMP-activated protein kinase in the heart, Diabetes 58 (2009) 2536-2546.

[75] L. Cao, X. Qin, M.R. Peterson, S.E. Haller, K.A. Wilson, N. Hu, X. Lin, S. Nair, J. Ren, G. He, CARD9 knockout ameliorates myocardial dysfunction associated with high fat diet-induced obesity, J. Mol. Cell Cardiol. 92 (2016) 185-195.

[76] I. Jialal, H. Kaur, S. Devaraj, Toll-like receptor status in obesity and metabolic syndrome: a translational perspective, J. Clin. Endocrinol. Metab. 99 (2014) 39-48.

[77] L.A. Velloso, F. Folli, M.J. Saad, TLR4 at the crossroads of nutrients, Gut Microbiota, and metabolic inflammation, Endocr. Rev. 36 (2015) 245-271.

[78] J.J. Kim, D.D. Sears, TLR4 and insulin resistance, Gastroenterol. Res. Pract. 2010 (2010).

[79] C. Jin, R.A. Flavell, Innate sensors of pathogen and stress: linking inflammation to obesity, J. Allergy Clin. Immunol. 132 (2013) 287-294.

[80] P. Plomgaard, K. Bouzakri, R. Krogh-Madsen, B. Mittendorfer, J.R. Zierath, B. K. Pedersen, Tumor necrosis factor-alpha induces skeletal muscle insulin resistance in healthy human subjects via inhibition of Akt substrate 160 phosphorylation, Diabetes 54 (2005) 2939-2945.

[81] J.K. Kim, Endothelial nuclear factor kappaB in obesity and aging: is endothelial nuclear factor kappaB a master regulator of inflammation and insulin resistance? Circulation 125 (2012) 1081-1083.

[82] W.L. Holland, B.T. Bikman, L.P. Wang, G. Yuguang, K.M. Sargent, S. Bulchand, T.A. Knotts, G. Shui, D.J. Clegg, M.R. Wenk, M.J. Pagliassotti, P.E. Scherer, S. A. Summers, Lipid-induced insulin resistance mediated by the proinflammatory receptor TLR4 requires saturated fatty acid-induced ceramide biosynthesis in mice, J. Clin. Investig. 121 (2011) 1858-1870.

[83] C.K. Glass, J.M. Olefsky, Inflammation and lipid signaling in the etiology of insulin resistance, Cell Metab. 15 (2012) 635-645.

[84] M.T. Waddingham, A.J. Edgley, H. Tsuchimochi, D.J. Kelly, M. Shirai, J. T. Pearson, Contractile apparatus dysfunction early in the pathophysiology of diabetic cardiomyopathy, World J. Diabetes 6 (2015) 943-960.

[85] K. Dutta, D.A. Podolin, M.B. Davidson, A.J. Davidoff, Cardiomyocyte dysfunction in sucrose-fed rats is associated with insulin resistance, Diabetes 50 (2001) 1186-1192.

[86] K.K. Hintz, J. Ren, Prediabetic insulin resistance is not permissive to the development of cardiac resistance to insulin-like growth factor I in ventricular myocytes, Diabetes Res. Clin. Pract. 55 (2002) 89-98.

[87] K.K. Hintz, N.S. Aberle, J. Ren, Insulin resistance induces hyperleptinemia, cardiac contractile dysfunction but not cardiac leptin resistance in ventricular myocytes, Int. J. Obes. Relat. Metab. Disord. 27 (2003) 1196-1203.

[88] F.S. Fein, Diabetic cardiomyopathy, Diabetes Care 13 (1990) 1169-1179.

[89] J.P. Morgan, Abnormal intracellular modulation of calcium as a major cause of cardiac contractile dysfunction, N Engl. J. Med. 325 (1991) 625-632.

[90] H. Hayashi, N. Noda, Cytosolic $\mathrm{Ca}^{2+}$ concentration decreases in diabetic rat myocytes, Cardiovasc. Res. 34 (1997) 99-103.

[91] L.E. Wold, K. Dutta, M.M. Mason, J. Ren, S.E. Cala, M.L. Schwanke, A. J. Davidoff, Impaired SERCA function contributes to cardiomyocyte dysfunction in insulin resistant rats, J. Mol. Cell. Cardiol. 39 (2005) 297-307.

[92] A. Malhotra, S. Penpargkul, F.S. Fein, E.H. Sonnenblick, J. Scheuer, The effect of streptozotocin-induced diabetes in rats on cardiac contractile proteins, Circ. Res. 49 (1981) 1243-1250.

[93] N. Takeda, I. Nakamura, T. Hatanaka, T. Ohkubo, M. Nagano, Myocardial mechanical and myosin isoenzyme alterations in streptozotocin-diabetic rats, Jpn. Heart J. 29 (1988) 455-463.

[94] V.L. Rundell, D.L. Geenen, P.M. Buttrick, P.P. de Tombe, Depressed cardiac tension cost in experimental diabetes is due to altered myosin heavy chain isoform expression, Am. J. Physiol. Heart Circ. Physiol. 287 (2004) H408-H413.

[95] D.J. Glenn, F. Wang, M. Nishimoto, M.C. Cruz, Y. Uchida, W.M. Holleran, Y. Zhang, Y. Yeghiazarians, D.G. Gardner, A murine model of isolated cardiac steatosis leads to cardiomyopathy, Hypertension 57 (2011) 216-222.

[96] L. Liu, X. Shi, K.G. Bharadwaj, S. Ikeda, H. Yamashita, H. Yagyu, J.E. Schaffer, Y. H. Yu, I.J. Goldberg, DGAT1 expression increases heart triglyceride content but ameliorates lipotoxicity, J. Biol. Chem. 284 (2009) 36312-36323.

[97] G. Wolkart, A. Schrammel, K. Dorffel, G. Haemmerle, R. Zechner, B. Mayer, Cardiac dysfunction in adipose triglyceride lipase deficiency: treatment with a PPARalpha agonist, Br. J. Pharmacol. 165 (2012) 380-389.

[98] A.J. Hoy, C.R. Bruce, S.M. Turpin, A.J. Morris, M.A. Febbraio, M.J. Watt, Adipose triglyceride lipase-null mice are resistant to high-fat diet-induced insulin resistance despite reduced energy expenditure and ectopic lipid accumulation, Endocrinology 152 (2011) 48-58.

[99] P.C. Kienesberger, T. Pulinilkunnil, J. Nagendran, M.E. Young, J.G. BognerStrauss, H. Hackl, R. Khadour, E. Heydari, G. Haemmerle, R. Zechner, E. E. Kershaw, J.R. Dyck, Early structural and metabolic cardiac remodelling in response to inducible adipose triglyceride lipase ablation, Cardiovasc. Res. 99 (2013) 442-451.

[100] T. Pulinilkunnil, P.C. Kienesberger, J. Nagendran, N. Sharma, M.E. Young, J. R. Dyck, Cardiac-specific adipose triglyceride lipase overexpression protects from cardiac steatosis and dilated cardiomyopathy following diet-induced obesity, Int. J. Obes. Lond. 38 (2014) 205-215.

[101] C.J. Knowles, M. Cebova, I.M. Pinz, Palmitate diet-induced loss of cardiac caveolin-3: a novel mechanism for lipid-induced contractile dysfunction, PLoS One 8 (2013) e61369.

[102] R.G. Parton, K. Simons, The multiple faces of caveolae, Nat. Rev. Mol. Cell. Biol. 8 (2007) 185-194. 
[103] R.G. Parton, M. Way, N. Zorzi, E. Stang, Caveolin-3 associates with developing T-tubules during muscle differentiation, J. Cell Biol. 136 (1997) 137-154.

[104] F. Galbiati, J.A. Engelman, D. Volonte, X.L. Zhang, C. Minetti, M. Li, H. Hou Jr., B. Kneitz, W. Edelmann, M.P. Lisanti, Caveolin-3 null mice show a loss of caveolae, changes in the microdomain distribution of the dystrophin-glycoprotein complex, and t-tubule abnormalities, J. Biol. Chem. 276 (2001) $21425-21433$.

[105] S.E. Woodman, D.S. Park, A.W. Cohen, M.W. Cheung, M. Chandra, J. Shirani, B. Tang, L.A. Jelicks, R.N. Kitsis, G.J. Christ, S.M. Factor, H.B. Tanowitz, M. P. Lisanti, Caveolin-3 knock-out mice develop a progressive cardiomyopathy and show hyperactivation of the p42/44 MAPK cascade, J. Biol. Chem. 277 (2002) 38988-38997.

[106] D.S. Park, S.E. Woodman, W. Schubert, A.W. Cohen, P.G. Frank, M. Chandra, J. Shirani, B. Razani, B. Tang, L.A. Jelicks, S.M. Factor, L.M. Weiss, H.B. Tanowitz, M.P. Lisanti, Caveolin-1/3 double-knockout mice are viable, but lack both muscle and non-muscle caveolae, and develop a severe cardiomyopathic phenotype, Am. J. Pathol. 160 (2002) 2207-2217.

[107] T. Hayashi, T. Arimura, K. Ueda, H. Shibata, S. Hohda, M. Takahashi, H. Hori, Y. Koga, N. Oka, T. Imaizumi, M. Yasunami, A. Kimura, Identification and functional analysis of a caveolin-3 mutation associated with familial hypertrophic cardiomyopathy, Biochem. Biophys. Res. Commun. 313 (2004) $178-184$.

[108] J. Oshikawa, K. Otsu, Y. Toya, T. Tsunematsu, R. Hankins, J. Kawabe, S. Minamisawa, S. Umemura, Y. Hagiwara, Y. Ishikawa, Insulin resistance in skeletal muscles of caveolin-3-null mice, Proc. Natl. Acad. Sci. USA 101 (2004)
$12670-12675$

[109] D.M. Muoio, T.R. Koves, Lipid-induced metabolic dysfunction in skeletal muscle, Novartis Found. Symp. 286 (2007) 24-38, discussion 38-46, 162-163, 196-203.

[110] D. Bonnet, D. Martin, L. Pascale De, E. Villain, P. Jouvet, D. Rabier, M. Brivet, J. M. Saudubray, Arrhythmias and conduction defects as presenting symptoms of fatty acid oxidation disorders in children, Circulation 100 (1999) 2248-2253.

[111] G. Schmilinsky-Fluri, V. Valiunas, M. Willi, R. Weingart, Modulation of cardiac gap junctions: the mode of action of arachidonic acid, J. Mol. Cell. Cardiol. 29 (1997) 1703-1713.

[112] R.H. Unger, L. Orci, Diseases of liporegulation: new perspective on obesity and related disorders, FASEB J. 15 (2001) 312-321.

[113] K. Drosatos, P.C. Schulze, Cardiac lipotoxicity: molecular pathways and therapeutic implications, Curr. Heart Fail. Rep. 10 (2013) 109-121.

[114] T.S. Park, I.J. Goldberg, Sphingolipids, lipotoxic cardiomyopathy, and cardiac failure, Heart Fail. Clin. 8 (2012) 633-641.

[115] J.S. Lally, L.A. Snook, X.X. Han, A. Chabowski, A. Bonen, G.P. Holloway, Subcellular lipid droplet distribution in red and white muscles in the obese Zucker rat, Diabetologia 55 (2012) 479-488.

[116] M.J. Morgan, Z.G. Liu, Crosstalk of reactive oxygen species and NF-kappaB signaling, Cell Res. 21 (2011) 103-115.

[117] R. Harmancey, H. Taegtmeyer, The complexities of diabetic cardiomyopathy: lessons from patients and animal models, Curr. Diabetes Rep. 8 (2008) 243-248. 